\title{
Application of an Automatic Control System of Photosynthetic Photon Flux Density for LED-Low Light Irradiation Storage of Green Plants
}

\author{
Kazuhiro Fujiwara ${ }^{1,2}$, Toshinari Sawada ${ }^{1}, Y_{0}$ oshikatsu Kimura ${ }^{1}$, and \\ Kenji Kurata $^{1}$
}

AdDitional INDEX wORDs. compensation point, light-emitting diode, PID control, $P P F D$, transplant

SumMARY. A light-emitting diode (LED)-low light irradiation (LLI) storage system was developed for suppressing the change in dry weight and maintaining the quality of green plants during long-term storage. In this system, the carbon dioxide $\left(\mathrm{CO}_{2}\right)$ exchange rate was maintained at zero by automatically adjusting the photosynthetic photon flux density (PPFD) with a proportional-integralderivative (PID) controller. The voltage supplied to the LEDs was controlled by the difference between the inflow $\left(400 \mu \mathrm{mol} \cdot \mathrm{mol}^{-1}\right)$ and outflow $\mathrm{CO}_{2}$ concentrations in the storage case. Grafted tomato (Lycopersicon esculentum; scion = 'House Momotaro'; rootstock = 'Anchor T') plug seedlings were stored at $10{ }^{\circ} \mathrm{C}$ for 35 days under four different LLI conditions as a system operating test: fixed red light irradiation at $2 \mu \mathrm{mol} \cdot \mathrm{m}^{-2} \cdot \mathrm{s}^{-1}$, PID-controlled red light irradiation with no blue light, and PID-controlled red light irradiation with blue light at 0.2 or $1.0 \mu \mathrm{mol} \cdot \mathrm{m}^{-2} \cdot \mathrm{s}^{-1}$. The results showed that the automatic PPFD control during LED-LLI helped suppress changes in dry weight during storage as expected. Furthermore, it was found that addition of a low percentage of blue light improved the morphological appearance of the seedlings and reduced the PPFD required to suppress the change in dry weight.

Light irradiation during storage has been shown to prolong storability of geranium (Pelargonium $\times$ hortorum) cuttings (Paton and Schwabe, 1987). Heins et al. $(1992,1994)$ also reported that low light irradiation (LLI) can preserve plug seedling quality during low temperature storage of tomato and 18 species of bedding plants. Further studies have suggested that a light intensity at which the net photosynthetic rate is maintained at zero (the light compensation point) is needed for suppressing changes in dry weight and preserving quality in eggplant (Solanum melongena) plug seedlings (Kozai et al., 1996) and in

${ }^{1}$ Graduate School of Agricultural and Life Sciences, The University of Tokyo, Bunkyo, Tokyo 113-8657, Japan.

${ }^{2}$ To whom reprint requests should be addressed. E-mail address: afuji@mail.ecc. u-tokyo.ac.jp

Acknowledgments. We wish to thank Mr. K. Takaku for experimental assistance. A part of the preliminary experiments was carried out at the Plant Production Engineering Laboratory (Prof. M. Iimoto) of Chiba University, Japan. This work was partly supported by the Japan Society for the Promotion of Science under Grants-in-Aid for Scientific Research (Scientific Research (B), No. 15380169). vitro broccoli (Brassica oleracea var. italica) plantlets (Kubota and Kozai, 1995) during LLI-low temperature storage.

Despite the potential usefulness of these findings, there are two important problems for the practical implementation of LLI-low temperature storage at the light compensation point (the point at which $\mathrm{CO}_{2}$ uptake balances $\mathrm{CO}_{2}$ release). First, the light compensation point must be determined by measuring the $\mathrm{CO}_{2}$ exchange rate of plants at the storage temperature and under different PPFDs. This must be done prior to each operation because the light compensation point can differ according to the plant species, growth stage, and condition. Second, because the light compensation is not constant

\begin{tabular}{llll}
\hline $\begin{array}{l}\text { Units } \\
\text { To convert } \\
\text { U.S. to SI, } \\
\text { multiply by }\end{array}$ & U.S. unit & SI unit & $\begin{array}{l}\text { To convert } \\
\text { SI to U.S., } \\
\text { multiply by }\end{array}$ \\
\hline 3.7854 & gal & $\mathrm{L}$ & 0.2642 \\
2.5400 & inch(es) & $\mathrm{cm}$ & 0.3937 \\
25.4000 & inch $(\mathrm{es})$ & $\mathrm{mm}$ & 0.0394 \\
6.4516 & inch $^{2}$ & $\mathrm{~cm}^{2}$ & 0.1550 \\
28,350 & $\mathrm{oz}$ & $\mathrm{mg}$ & $3.5274 \times 10^{-5}$ \\
$\left({ }^{\circ} \mathrm{F}-32\right) \div 1.8$ & ${ }^{\circ} \mathrm{F}$ & ${ }^{\circ} \mathrm{C}$ & $\left(1.8 \times{ }^{\circ} \mathrm{C}\right)+32$
\end{tabular}


during storage, determining it prior to storage may not prevent changes in dry weight. In fact, green plants acclimatize to low light conditions in a few days, leading to a gradual reduction in the light compensation point (Björkman and Hormgren, 1963; Fonteno and McWilliams, 1978).

For these reasons, we built an LED-LLI storage system, capable of irradiating red light only and/or red and blue mixed light, wherein the PPFD is automatically controlled by a PID controller that maintains the $\mathrm{CO}_{2}$ exchange rate at zero. LEDs are one of the most appropriate light sources for such a system because the PPFD can be easily controlled at the plant canopy level by regulating the supplied voltage. We tested this system with grafted tomato plug seedlings to verify its function. At the same time, we investigated whether an additional blue light into red light could improve the quality of the stored seedling under the conditions that PPFD and blue light percentage changed with time during storage. We found that the mixed light irradiation from red and blue LEDs at constant blue light percentages was more effective than red light alone for preserving the quality of grafted tomato plug seedlings under a constant PPFD condition (Fujiwara et al., 2003).

\section{LED-LLI storage system under automatic PPFD control}

System configuration. Green plants were stored in a transparent acryl-resin case $(200 \mathrm{~mm}$ wide $\times 200$ $\mathrm{mm}$ deep $\times 250 \mathrm{~mm}$ high; PPFD-base transmittance $=99 \%$ for red light,
$98 \%$ for blue light) covered with a light-diffusing film (PPFD-base transmittance $=86 \%$ for red light, $87 \%$ for blue light) on the top surface and aluminum foil on the four lateral surfaces (Fig. 1). Mixed gas composed of nitrogen $\left[\mathrm{N}_{2}\left(800 \mathrm{mmol} \cdot \mathrm{mol}^{-1}\right)\right]$, oxygen $\left[\mathrm{O}_{2}\left(200 \mathrm{mmol} \cdot \mathrm{mol}^{-1}\right)\right]$, and $\mathrm{CO}_{2}\left(400 \mu \mathrm{mol} \cdot \mathrm{mol}^{-1}\right)$ was supplied to the storage case at $6.0 \mathrm{~L} \cdot \mathrm{h}^{-1}$. The flow rate was adjusted by a flow controller (model 2203; Kofloc Co., Kyoto, Japan) and measured with a mass flow meter (model 3850; Kofloc Co.).

The voltage supplied to the LEDs was automatically controlled using a PID controller (E5CK; Omron Corp., Tokyo) by the difference between the inflow $\left(\mathrm{C}_{\text {in }}=400 \mu \mathrm{mol} \cdot \mathrm{mol}^{-1}\right)$ and outflow $\left(\mathrm{C}_{\text {out }}\right) \mathrm{CO}_{2}$ concentrations in the storage case so that $\mathrm{CO}_{2}$ exchange rate was maintained at zero. $\mathrm{C}_{\text {in }}$ and $\mathrm{C}_{\text {out }}$ were measured with infrared $\mathrm{CO}_{2}$ analyzers (ZFP9GB1 1-Z; Fuji Electric Co., Tokyo) that were calibrated against standard $\mathrm{N}_{2}$-based $\mathrm{CO}_{2}$ gases. A dehumidifier (silica gel pellets enclosed in a tube) was placed prior to the infrared $\mathrm{CO}_{2}$ analyzer for $\mathrm{C}_{\text {out }}$ in order to remove water vapor that was an interfering substance against the infrared $\mathrm{CO}_{2}$ analyzer. The light compensation point is a PPFD level, measured at the plant level, when the difference between $\mathrm{C}_{\text {in }}$ and $\mathrm{C}_{\text {out }}$ is zero with an assumption that the rates of non-plant $\mathrm{CO}_{2}$ release and absorption are negligible.

LED ARRAY, AUTOMATIC PPFD CONTROL, AND ESTABLISHMENT OF PID PARAMETERS. Eighty red [peak $=630$ $\mathrm{nm}$, peak width at half height $=18 \mathrm{~nm}$ (TLRH157P; Toshiba Semiconductor
Co., Tokyo) $]$ and 70 blue $[$ peak $=470$ $\mathrm{nm}$, peak width at half height $=30 \mathrm{~nm}$ (NSPB510S; Nichia Corp., Tokushima, Japan)] LEDs were equally spaced on a rectangular, universal circuit board $(245 \times 320 \mathrm{~mm})$ so that the LED array provided an almost even composition of wavelengths at the canopy level. Red and blue LEDs were connected in 10 parallel lines, each containing eight and seven LEDs, respectively. Little difference in the composition of wavelengths was observed with a spectroradiometer (MS-720; Eko Instruments Co., Tokyo) between the canopy levels right above the four corner plugs and that right above the center plug for all lighting treatments when the total PPFDs, which were the mean values of nine points at the canopy level right above the nine plugs, for each treatment were equal to 2.0 $\mu \mathrm{mol} \cdot \mathrm{m}^{-2} \cdot \mathrm{s}^{-1}$. Slightly smaller PPFDs at the canopy level right above the four corner plugs were observed compared to that right above the center plug by $1 \%$ to $2 \%$ with a PPFD meter (LI190SA with LI-250; Li-Cor, Lincoln, Nebr.).

The PPFD at the plant canopy level was controlled using a PID controller. The output of the PID controller $\left(\mathrm{V}_{\mathrm{act}}\right)$ was determined by the difference (control error) between the set point $\left(\mathrm{V}_{\mathrm{sp}}\right)$ corresponding to the desired $\mathrm{C}_{\text {out }}\left(400 \mu \mathrm{mol} \cdot \mathrm{mol}^{-1}\right)$ and the feedback signal $\left(\mathrm{V}_{\mathrm{fdb}}\right)$ corresponding to the current $\mathrm{C}_{\text {out }}$. $\mathrm{V}_{\text {act }}$ was transmitted to a DC power supply (PMC35-1A; Kikusui Electronics Corp., Kanagawa, Japan) and 3.5-fold amplified according to the control specifications of the power supply. The gain $\left(\mathrm{V}_{\mathrm{act}} \times 3.5\right)$

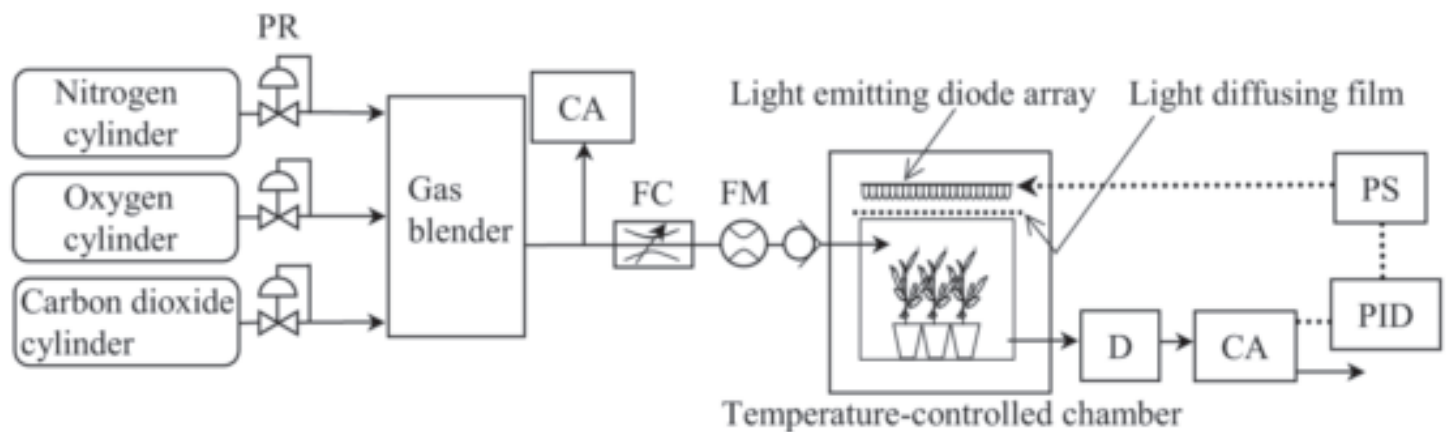
PR: Pressure regulator
CA: Infrared carbon dioxide analyzer
FC: Flow controller
FM: Mass flow meter
D: Dehumidifier
PID: Proportional-integral-derivative controller
PS: Direct current power supply

Fig. 1. Schematic diagram of the light emitting diode-low light irradiation storage system under automatic photosynthetic photon flux density control. 


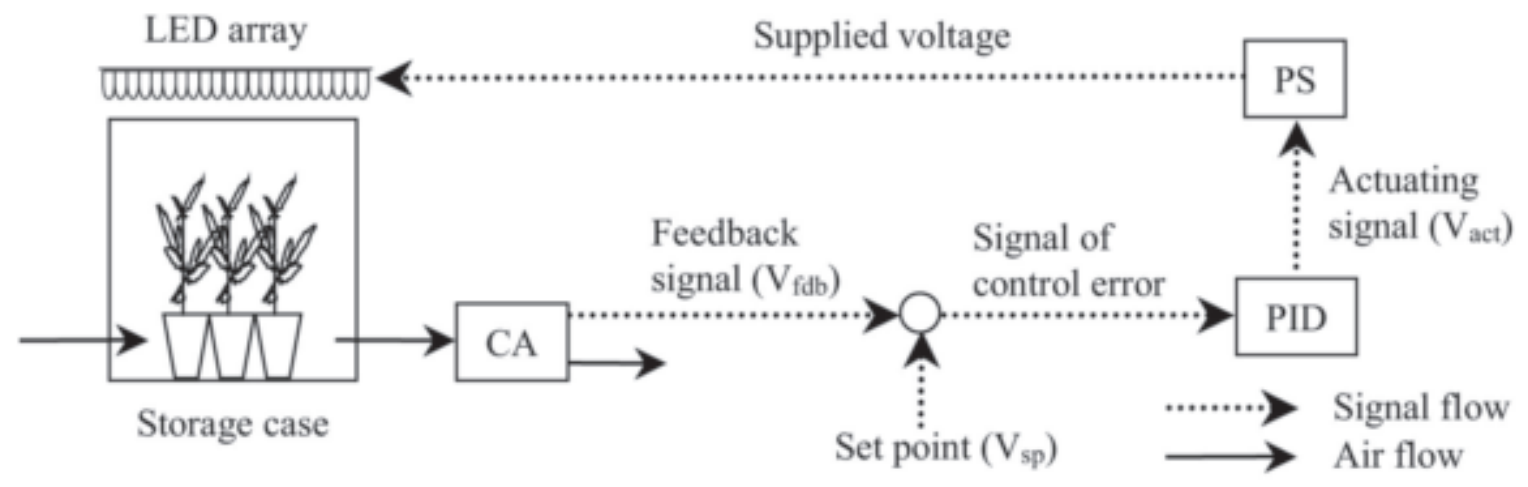

CA: Infrared carbon dioxide analyzer

PID: Proportional-integral-derivative controller PS: Direct current power supply

Fig. 2. Schematic diagram of the automatic photosynthetic photon flux density control for the light emitting diode-low light irradiation storage system.

was determined so that the maximum PPFD from the red LEDs at the plant canopy level became $11 \mu \mathrm{mol} \cdot \mathrm{m}^{-2} \cdot \mathrm{s}^{-1}$ (the details will be described later). The amplified voltage was supplied to the LED array (Fig. 2). Although current control is generally applied for LEDs, voltage control was applied in this system to avoid a possible excessive current supply, which could be caused by a sudden variation in load. There was no possibility that the maximum output-voltage variation $(3 \mathrm{mV}$, specified in the catalog) for the power supply caused any severe damage to the red LEDs due to load variation, while there was a possibility that the maximum output-current variation ( $5 \mathrm{~mA}$, specified in the catalog) did, because the maximum forward voltage and current for the red LEDs were 2.5 $\mathrm{V}$ and $50 \mathrm{~mA}$, respectively.

An optimal combination of PID parameters (proportional band $=\mathrm{PB}$; integral time $=T_{i}$; and derivative time $=\mathrm{T}_{\mathrm{d}}$ ) was simply determined by a series of 24-h storage experiments at $10 \pm$ $0.5{ }^{\circ} \mathrm{C}$ with $\mathrm{C}_{\text {in }}$ of $400 \mathrm{umol} \cdot \mathrm{mol}^{-1}$ using leaves of japanese mallotus (Mallotus japonicus) (leaf area $=40$ $\mathrm{cm}^{2}$ ) as a model plant. Three levels of PB $(15 \%, 30 \%$, or $50 \%), \mathrm{T}_{\mathrm{i}}(900$, 1800 , or $3600 \mathrm{~s})$, and $\mathrm{T}_{\mathrm{d}}(0,900$, or $1800 \mathrm{~s}$ ) were tested. The combinations were evaluated better as the shortterm fluctuation of PPFD and the time required for $\mathrm{C}_{\text {out }}$ to reach a stable level were smaller. The short-term fluctuation of PPFD decreased with increasing $\mathrm{PB}$ or decreasing $\mathrm{T}_{\mathrm{d}}$, and the time required for $\mathrm{C}_{\text {out }}$ to reach a stable level decreased with increasing $\mathrm{T}_{\mathrm{i}}$. Based on the results, a combination of $\mathrm{PB}=50 \%, \mathrm{~T}_{\mathrm{i}}=3600 \mathrm{~s}$, and $\mathrm{T}_{\mathrm{d}}=0 \mathrm{~s}$ was chosen as an optimal combination for the present system.

\section{System operating test combined with a storage experiment}

\section{Materials and methods}

Grafted tomato seedlings, which were sown on 6 Feb., grafted on 2 Mar., and grown in a 72-plug tray for $13 \mathrm{~d}$ in a plastic house under sunlight, were obtained on 16 Mar. from a commercial seedling supplier (Berg Earth Co., Ehime, Japan). Before storage, 45 (nine seedlings $\times$ five groups) out of 72 seedlings were carefully selected and evenly split into four different lighting treatments and for an initial determination of seedling growth parameters so that there would not be significant differences in stem lengths or number of fully expanded leaves. The nine seedlings for each lighting treatment were placed in separate nineplug (three $\times$ three) trays of the same root dimensions as the 72 -plug tray and were subirrigated for $1 \mathrm{~h}$ before being placed in each storage case.

Seedlings were stored for $35 \mathrm{~d}$ at $10 \pm 0.5{ }^{\circ} \mathrm{C}$ and greater than $95 \%$ relative humidity. Each storage case containing nine seedlings was placed directly below an LED array. Four different lighting treatments were prepared: fixed red light irradiation at $2 \mathrm{\mu mol} \cdot \mathrm{m}^{-2} \cdot \mathrm{s}^{-1}$ at the canopy level of the seedlings $(14 \mathrm{~cm}$ above the storage case bottom) (R2B0)]; PIDcontrolled red light irradiation ( $\mathrm{RC}$ ) with no blue light irradiation ( $\mathrm{RCBO}$ ); $\mathrm{RC}$ with fixed blue light irradiation at $0.2 \mu \mathrm{mol} \cdot \mathrm{m}^{-2} \cdot \mathrm{s}^{-1}(\mathrm{RCB} 0.2)$; and
$\mathrm{RC}$ with fixed blue light irradiation at $1.0 \mu \mathrm{mol} \cdot \mathrm{m}^{-2} \cdot \mathrm{s}^{-1}(\mathrm{RCBl})$. Lighting for all treatments was continuous (24/0 h light/dark photoperiod). The maximum controllable red-light PPFD at the canopy level of the seedlings was $11 \mu \mathrm{mol} \cdot \mathrm{m}^{-2} \cdot \mathrm{s}^{-1}$ for RC treatments, which corresponded to the maximum allowable input voltage to the red LED. Based on previous storage experiments with grafted tomato plug seedlings (Fujiwara et al., 2001, 2003), the maximum PPFD of $11 \mathrm{\mu mol} \cdot \mathrm{m}^{-2} \cdot \mathrm{s}^{-1}$ at the canopy level of the seedlings was considered to be sufficient for maintaining the $\mathrm{CO}_{2}$ exchange rate of the seedlings at zero.

The stem length, number of fully expanded leaves, and a visual quality score were measured for all seedlings on days $0,7,14,21,28$, and $35 \mathrm{~d}$ after the start of storage. The visual quality was assigned a score between 4 (in which almost all leaves were green) and 0 (in which most leaves were brown and/or some leaves were showing necrosis) (Fujiwara et al., 2001). The leaf color difference of the nine seedlings in each treatment between day 0 and each measurement day was determined with a color reader (CR-13; Konica Minolta, Tokyo). On day 35, all seedlings were harvested and separated into leaves, stem, and roots. The dry weight of the aerial and subterranean parts, and leaf area per seedling were measured. The nine seedlings allotted to the before storage measurement were used for the estimation of day 0 dry weight and leaf area. All data were subjected to analysis of variance and least significant difference test using the JMP software package (SAS 

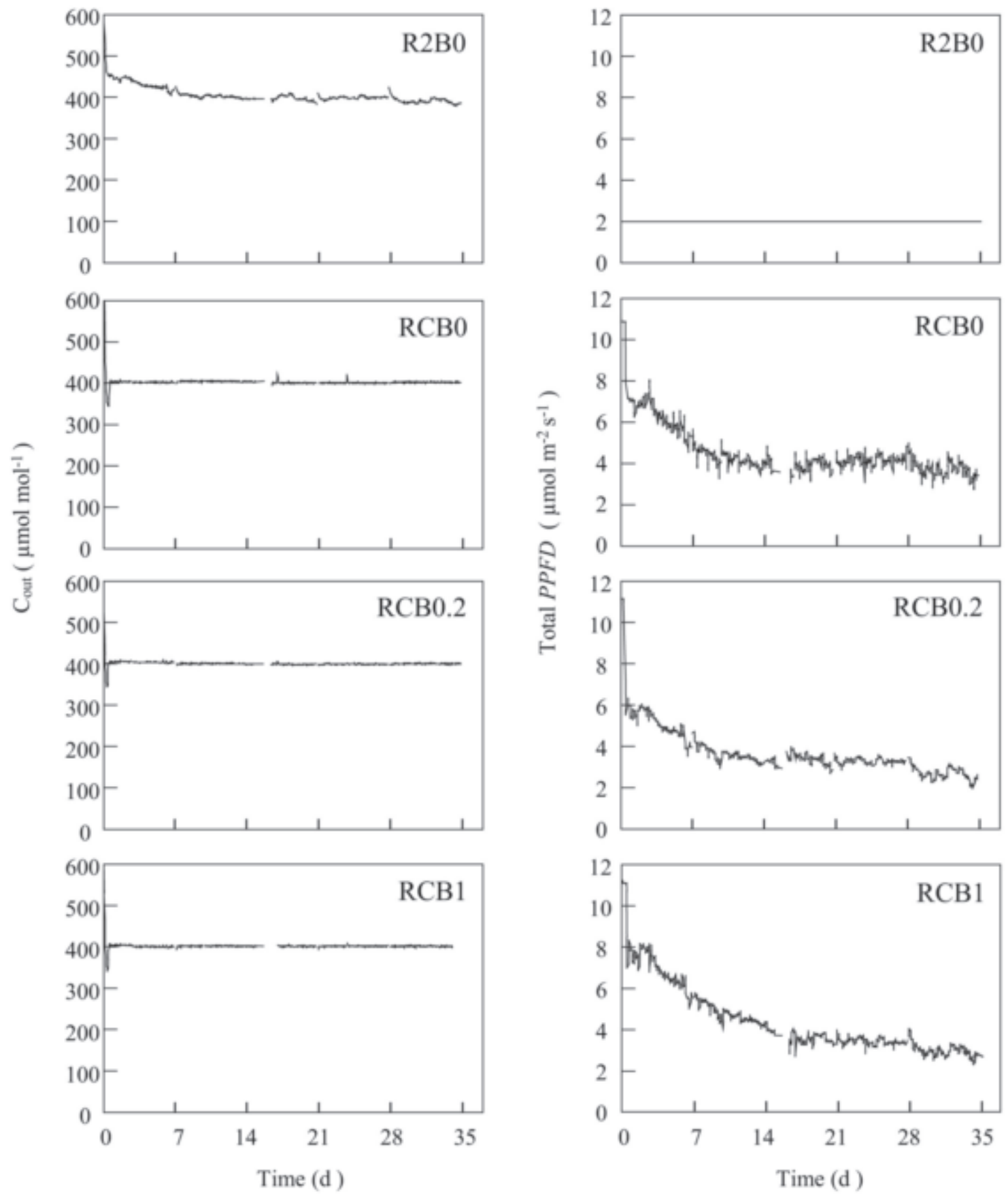

Fig. 3 Time course of the carbon dioxide $\left(\mathrm{CO}_{2}\right)$ concentration of outflow air $\left(\mathrm{C}_{\text {out }}\right)$ from the storage case (left) and the total photosynthetic photon flux density (PPFD) at the canopy level in the storage case (right) in each treatment during light emitting diode-low light irradiation low temperature storage of grafted tomato plug seedlings. R2B0 = red light irradiation at $2 \mu \mathrm{mol} \cdot \mathrm{m}^{-2} \cdot \mathrm{s}^{-1}$ at the canopy level of the seedlings, RCB0 = red light irradiation controlled with a proportional-integralderivative (PID) controller, RCB0.2 = PID-controlled red light irradiation with blue light irradiation at $0.2 \mu \mathrm{mol} \cdot \mathrm{m}^{-2} \cdot \mathrm{s}^{-1}$, $\mathrm{RCB1}=\mathrm{PID}$-controlled red light irradiation with blue light irradiation at $1.0 \mu \mathrm{mol} \cdot \mathrm{m}^{-2} \cdot \mathrm{s}^{-1}$.

Institute, Cary, N.C.) to determine if there were significant differences at the $5 \%$ level between the mean values for the different treatments.

The $\mathrm{C}_{\text {out }}$ and supplied voltage to the LED array for each treatment were recorded during storage. The supplied voltage was used for determination of the total PPFD at the canopy level in the storage case. Recorded $\mathrm{C}_{\text {out }}$ and supplied voltage to the LED array were omitted for a few hours after and during the renewal of the dehumidifier placed prior to the infrared $\mathrm{CO}_{2}$ analyzer and the 7-d-interval measurements since the recorded $\mathrm{C}_{\text {out }}$ and supplied voltage to the LED array for the period did not reflect the actual $\mathrm{CO}_{2}$ exchange rate of the seedlings. In addition, recorded $\mathrm{C}_{\text {out }}$ and supplied voltage data on day 16 were lost due to the suspension of electric power.

\section{Results and discussion}

System PERFORMANCE. Except for the first $12 \mathrm{~h}$, the $\mathrm{C}_{\text {out }}$ in all the redlight PPFD-PID-controlled treatments 
Table 1. Aerial, subterranean, and total dry weights of the grafted tomato plug seedlings before storage and after the $35 \mathrm{~d}$ of storage. Values represent means \pm SE $(\mathbf{n}=9)$.

\begin{tabular}{lccl}
\hline & \multicolumn{3}{c}{ Dry wt $(\mathrm{mg} / \text { seedling })^{\mathrm{y}}$} \\
\cline { 2 - 4 } Treatment $^{\mathrm{z}}$ & Aerial & Subterranean & Total \\
\hline BS & $82.6 \pm 4.68^{\mathrm{x}}$ & $8.8 \pm 0.07$ & $91.4 \pm 5.17$ \\
R2B0 & $59.7 \pm 2.65 \mathrm{~b}^{*}$ & $10.2 \pm 0.13 \mathrm{~b}$ & $69.9 \pm 3.57 \mathrm{~b}^{*}$ \\
RCB0 & $72.5 \pm 6.14 \mathrm{a}$ & $11.4 \pm 0.10 \mathrm{~b}$ & $83.9 \pm 6.96 \mathrm{ab}$ \\
RCB0.2 & $78.4 \pm 3.75 \mathrm{a}$ & $13.1 \pm 0.14 \mathrm{a}^{*}$ & $91.5 \pm 4.79 \mathrm{a}$ \\
RCB1 & $77.9 \pm 4.17 \mathrm{a}$ & $13.4 \pm 0.11 \mathrm{a}^{*}$ & $91.3 \pm 4.89 \mathrm{a}$ \\
\hline
\end{tabular}

${ }^{2} \mathrm{BS}=$ before storage, $\mathrm{R} 2 \mathrm{~B} 0=$ red light irradiation at $2 \mu \mathrm{mol} \cdot \mathrm{m}^{-2} \cdot \mathrm{s}^{-1}$ at the canopy level of the seedlings, $\mathrm{RCB} 0=$ red light irradiation controlled with a proportional-integral-derivative (PID) controller, RCB0.2 = PID-controlled red light irradiation with blue light irradiation at $0.2 \mu \mathrm{mol} \cdot \mathrm{m}^{-2} \cdot \mathrm{s}^{-1}, \mathrm{RCBl}=\mathrm{PID}$-controlled red light irradiation with blue light irradiation at $\mathrm{l} .0 \mathrm{\mu mol} \cdot \mathrm{m}^{-2} \cdot \mathrm{s}^{-1}$.

$\mathrm{y} 1 \mathrm{mg}=3.5274 \times 10^{-5} \mathrm{oz}$.

${ }^{x}$ Means with different letters are significantly different at the $5 \%$ level within columns according to the least significant difference test. Means with an asterisk $\left({ }^{*}\right)$ are significantly different from those before storage at the $5 \%$ level according to $t$ test.

(RC treatments) were satisfactorily maintained at around $400 \mathrm{umol} \cdot \mathrm{mol}^{-1}$ during storage (Fig. 3). The total dry weights of stored seedlings on day 35 in the RC treatments were not significantly different than those before storage (Table 1). These results indicated that the PID control of PPFD during LED-LLI storage contributed to the suppression of the dry weight change of the stored seedlings. On the other hand, the $\mathrm{C}_{\text {out }}$ in the constant PPFD treatment (R2B0) gradually dropped from 450 to $400 \mu \mathrm{mol} \cdot \mathrm{mol}^{-1}$ between days 1 and 14 and then remained stable at approximately $400 \mu \mathrm{mol} \cdot \mathrm{mol}^{-1}$ after day 14 . The average $\mathrm{C}_{\text {out }}$ in $\mathrm{R} 2 \mathrm{BO}$ exceeded the $\mathrm{C}_{\text {in }}$ by nearly $10 \mu \mathrm{mol} \cdot \mathrm{mol}^{-1}$, which resulted in a significant dry weight loss of the seedlings (Table 1 ). The dry weight loss in the constant PPFD treatment (R2B0) demonstrates the difficulty in preventing changes in dry weight during storage by using the constant PPFD determined as the light compensation point prior to storage.

The total PPFDs in the RC treatments gradually dropped between days 1 and 14, remained stable between days 14 and 29, and finally showed a tendency to fall after day 29 (Fig. 3). The gradual drop in PPFD (i.e., light compensation point) during the first 2 weeks of storage appears to be due to low light acclimatization of the tomato seedlings. Similar observations were reported with some growing plants under normal cultivation temperatures by other researchers (Björkman and Hormgren, 1963; Fonteno and McWilliams, 1978). The fall of PPFD for the last week of storage may reflect a decline in the photosynthetic functions of the seedlings after a longterm storage; seedlings with reduced photosynthetic function may require a greater PPFD for a gross photosynthetic rate to compensate for their respiration rate. A similar light compensation point time changed dynamics during the storage of harvested chervil
(Anthriscus cerefolium) plants, and tomato seedlings were suggested by previous studies of $\mathrm{C}_{\text {out }}$ by Fujiwara et al. (1999, 2001).

The LED-LLI storage system under automatic PPFD control was proposed to suppress the dry weight change by maintaining the $\mathrm{CO}_{2}$ exchange rate of stored green plants at almost zero. The results of our tests indicated that the system functioned satisfactorily as designed.

EFFECT OF AN ADDITIONAL BLUE LIGHT. Seedlings in the RC treatments on day 35 had a significantly greater stem length, a higher number of fully expanded leaves, and a larger leaf area than those before storage (Table 2). A combination of blue and red-LEDs was found to be able to suppress the stem elongation (Brown et al., 1995), increase the leaf number (Brown et al., 1995), expand the leaf area (Brown et al., 1995), and increase the dry weight (Brown et al., 1995; Goins et al., 1997; Yorio et al., 2001) under normal cultivation temperatures (22 to $\left.26^{\circ} \mathrm{C}\right)$ and PPFDs $(273-350$ umol $\left.\cdot \mathrm{m}^{-2} \cdot \mathrm{s}^{-1}\right)$. The above physiological changes were not observed in the present experiment. Effects of a blue light addition into red light may differ largely according to the temperature and PPFD.

Morphologically, leaves in RCBI and RCB0.2 looked vigorous even on day 25 and day 35 compared with those in RCB0 and R2B0, which had slightly drooped. There was no apparent visual quality score and color differences with an increased percentage of blue light.

Total PPFDs in the RC treatments were mostly stable at around 4 umol. $\mathrm{m}^{-2} \cdot \mathrm{s}^{-1}$ between days 14 and 28 (Fig. 3 ).

Table 2. Stem length, number of fully expanded leaves (NFEL), leaf area, leaf color difference $(\Delta E \times a b)$, and visual quality score (VQS) of grafted tomato plug seedlings before storage and after $35 \mathrm{~d}$ of storage. Values represent means \pm SE $(\mathrm{n}=9)$.

\begin{tabular}{|c|c|c|c|c|c|}
\hline Treatment $^{\mathrm{z}}$ & $\begin{array}{c}\text { Stem } \\
\text { length }(\mathrm{mm})^{\mathrm{y}}\end{array}$ & $\begin{array}{l}\text { NFEL } \\
\text { (no.) }\end{array}$ & $\begin{array}{c}\text { Leaf area } \\
\left(\mathrm{cm}^{2} / \text { seedling }\right)^{\mathrm{y}}\end{array}$ & $\Delta E \times a b$ & $\mathrm{VQS}^{\mathrm{x}}$ \\
\hline BS & $73 \pm 2.4^{w}$ & $3.9 \pm 0.12$ & $18.5 \pm 1.29$ & $0.0 \pm 0.00$ & $4.0 \pm 0.00$ \\
\hline RCB0 & $94 \pm 4.5 b^{*}$ & $5.1 \pm 0.25 \mathrm{a}^{*}$ & $25.4 \pm 1.64 \mathrm{a}^{*}$ & $10.5 \pm 1.25 \mathrm{a}^{*}$ & $2.6 \pm 0.18 \mathrm{ab}^{*}$ \\
\hline $\mathrm{RCB} 0.2$ & $107 \pm 4.5 \mathrm{a}^{*}$ & $5.2 \pm 0.18 \mathrm{a}^{*}$ & $27.5 \pm 2.06 \mathrm{a}^{*}$ & $11.0 \pm 1.11 \mathrm{a}^{*}$ & $2.6 \pm 0.18 \mathrm{ab}^{*}$ \\
\hline $\mathrm{RCBl}$ & $96 \pm 3.1 b^{*}$ & $5.1 \pm 0.22 \mathrm{a}^{*}$ & $29.2 \pm 2.07 \mathrm{a}^{*}$ & $8.9 \pm 0.89 \mathrm{a}^{*}$ & $2.8 \pm 0.22 \mathrm{a}^{*}$ \\
\hline
\end{tabular}


The mean value of total PPFD at every 10 min during storage except for the first $12 \mathrm{~h}$ for RCB0 $\left(4.47 \mu \mathrm{mol} \cdot \mathrm{m}^{-2} \cdot \mathrm{s}^{-1}\right)$ was significantly greater than those for RCB0.2 (3.64 $\left.\mathrm{\mu mol} \cdot \mathrm{m}^{-2} \cdot \mathrm{s}^{-1}\right)$ and RCBI $\left(4.25 \mathrm{umol} \cdot \mathrm{m}^{-2} \cdot \mathrm{s}^{-1}\right)$ at the $5 \%$ level according to $t$ test, respectively. The result showed that the addition of a low percentage of blue light reduced the PPFD required for suppressing the dry weight change. Goins et al. (1997) showed that wheat cultivated under red LEDs supplemented with blue light from fluorescent lamps had a higher net leaf photosynthetic rate than in wheat grown under only red LEDs, with approximately equal $P P F D$ at $350 \mathrm{\mu mol} \cdot \mathrm{m}^{-2} \cdot \mathrm{s}^{-1}$.

These results indicate that the addition of a low percentage of blue light reduced the PPFD needed to maintain the $\mathrm{CO}_{2}$ exchange rate of the tomato seedlings near zero. In addition, the blue light appeared to have positive effects on leaf morphological appearance (vigorous leaves without drooping), although this was not directly measured in the current evaluations of visual quality. Based on these findings, it is worthwhile to examine the feasibility of incorporating a low proportion of blue LEDs in the LED array for the LED-LLI storage system under automatic PPFD control. The optimal amount of blue light to apply for different kinds of green plants remains to be investigated.

\section{Literature cited}

Björkman, O. and P. Hormgren. 1963. Adaptability of the photosynthetic apparatus to light intensity in ecotypes from exposed and shaded habitats. Physiol. Plant. 16:889-914.

Brown, C.S., A.C. Schuerger, and J.C. Sager. 1995. Growth and photomorphogenesis of pepper plants under red lightemitting diodes with supplemental blue or far-red lighting. J. Amer. Soc. Hort. Sci. 120:808-813

Fonteno, W.C. and E.L. McWilliams. 1978. Light compensation points and acclimatization of four tropical foliage plants. J. Amer. Soc. Hort. Sci. 103:52-56.

Fujiwara, K., S. Isobe, and M. Iimoto. 2001. Optimum conditions of low light irradiation-CA storage for quality preservation of grafted tomato plug seedlings (in Japanese with English abstract and captions). Environ. Control Biol. 39:111-120.

Fujiwara, K., Y. Kimura, and K. Kurata. 2003. Effect on the quality of grafted tomato plug seedlings of blue-light PPFD percentage during red and blue LEDs low light irradiation storage (in Japanese with English abstract and captions). Environ. Control Biol. 41:361-368.

Fujiwara, K., K. Takaku, and M. Iimoto. 1999. Optimum conditions of low light irradiation-CA storage for preservation of the visual quality of postharvest whole chervil (Anthriscuscerefolium L.) (in Japanese with English abstract and captions). Environ. Control Biol. 37:203-210.
Goins, G.D., N.C. Yorio, M.M. Sanwo, and C.S. Brown. 1997. Photomorphogenesis, photosynthesis, and seed yield of wheat plants grown under red lightemitting diodes (LEDs) with and without supplemental blue lighting. J. Expt. Bot. 48:1407-1413.

Heins, R., N. Lange, and T.F. Wallace, Jr. 1992. Low-temperature storage of bedding-plant plugs, p. 45-64. In: K. Kurata and T. Kozai (eds.). Transplant production systems. Kluwer, Dordrecht, The Netherlands.

Heins, R., N. Lange, T.F. Wallace, Jr., and W. Carlson. 1994. Plug storage. Greenhouse Grower, Willoughby, Ohio.

Kozai, T., C. Kubota, K. Sakami, K. Fujiwara, and Y. Kitaya. 1996. Growth suppression and quality preservation of eggplant plug seedlings by low temperature storage under dim light (in Japanese with English abstract and captions). Environ. Control Biol. 34:135-139.

Kubota, C. and T. Kozai. 1995. Lowtemperature storage of transplants at the light compensation point: Air temperature and light intensity for growth suppression and quality preservation. Sci. Hort. 61:193-204.

Paton, F. and W.W. Schwabe. 1987. Storage of cuttings of Pelargonium $\times$ hortorum Bailey. J. Hort. Sci. 62:79-87.

Yorio, N.C., G.D. Goins, H.R. Kagie, R.M. Wheeler, and J.C. Sager. 2001. Improving spinach, radish, and lettuce growth under red light-emitting diodes (LEDs) with blue light supplementation. HortScience $36: 380-383$ 